Research Article

\title{
Formulation Development and Evaluation of Itraconazole Ocular In-situ Gel for Enhancement of Ocular Bioavailability: In-vitro Antifungal Activities Assessment
}

\author{
B.Padmasri ${ }^{*}$, R.Nagaraju ${ }^{2}$ \\ 1. Department of Pharmaceutical Technology, Sri Venkateswara College of Pharmacy, Etherla, Srikakulam, India. \\ 2.Department of Pharmaceutics, Institute of Pharmaceutical Technology, Sri Padmavathi Mahila, Viswa Vidylayam, Tirupati, India. \\ *Corresponding author's E-mail: padmasripharma@gmail.com
}

Received: 21-10-2020; Revised: 26-12-2020; Accepted: 03-01-2021; Published on: 15-01-2021.

\section{ABSTRACT}

Ophthalmic In-situ gel systems refers to polymer solution which can be administered as liquid and undergoes a sol-to-gel transition upon exposure to physiological environment i.e., $\mathrm{pH}$, Temperature, ions in the lachrymal fluid. The main important aim of the current study was ocular itraconazole in situ gel systems development and evaluation for its enhancing ocular bioavailability and in-vitro antifungal activity assessment. The keratomycosis is a chronic illness that can may leads to vision loss if not treated effectively. Itraconazole is low soluble drug due to this nature in present study we selected solid dispersion formulation (F12) to prepare in-situ gelling formulations of itraconazole. The $\mathrm{pH}$-triggered in-situ gel formulations were prepared by using different grades of polymers like Carbopol along with of HPMC. The prepared formulations were assessed to know physical appearance, pH, viscosity, content of drug, gelling capacity and time, in-vitro permeation studies, rheological properties and antifungal studies. All the prepared formulations are exhibiting quite consistent drug content. Furthermore in-vitro studies of drug release and antifungal activity of these formulations were also evaluated. Drug release study of all the formulations showed sustained release properties. The antimycotic effectiveness of the optimized preparation against C.albicans and Asperigillus niger confirmed that designed formulation has enhanced effect and retained its properties against fungal infection. In conclusion, hence formulation (F3) was selected as optimized formulations could be offered as shows potential approach for ocular drug delivery for the treatment of fungal keratitis to overcome the drawbacks of conventional ophthalmic solutions.

Keywords: Itraconazole, Ocular drug delivery, In-situ gels, Carbopol 934, HPMC.

QUICK RESPONSE CODE $\rightarrow$

DOI:

10.47583/ijpsrr.2021.v66i01.022

DOI link: http://dx.doi.org/10.47583/ijpsrr.2021.v66i01.022

\section{INTRODUCTION}

$\mathrm{O}$

ne of the principal predicaments faced in ophthalmic therapeutics is the attainment and retention of optimal ophthalmic drug concentration at the place of action, which is undermined predominantly on account of pre corneal loss resultant a diminutive ocular absorption of drug fraction such as only $10 \%$ drug concentrations available at the place of action within the eye $\mathrm{e}^{1}$. Various ophthalmic preparations like drops, gels, balms or ointments and polymeric ocular inserts have been explored trying to broaden the ocular residence period of drug for ophthalmic therapy ${ }^{2}$. The effectual dosage administer might be distorted by amplifying the retention period of ophthalmic drug by utilizing in-situ gel forming methods. Ophthalmic drug delivery is an incredibly fascinating and highly challenging goal in the management of ophthalmic therapy ${ }^{3,4}$.

The ophthalmic drops have extremely low bioavailability because of their quick washout during lacrimation (tears pool because of poor drainage) in eyes. The majority of the systems are applied as suspensions or solutions. The fast pre corneal quick elimination was observed by means of conservative ophthalmic preparations ends in poor therapeutics bioavailability. Ease of drug management in case of gel forms and highly viscous solutions impede its utilization and compliance of patient. The obscured vision and the lacrimation are related with the drug dosage involving within the gel form.

Hence, these might be conquering by manufacturing the medicine as a formulation that goes through immediate insitu gelation upon administration to the eyes. They go through gelation after drug instillation because of physicochemical alterations take place in the eyes. It builds the precorneal contact time and improved bioavailability of preparation can be accomplished by formulating in-situ gel systems. The present study describes "Development and evaluation of itraconazole loaded ocular In-situ gel formulations for enhancing ocular bioavailability"

\section{METERIALS AND METHODS}

Itraconazole was acquired from Glenmark Pharma private Ltd, Mumbai, India. All the polymers received were of pharmaceutical grade (HPMC K4, HPMC LVCR-100 are obtained from Lepid Life Sciences Pvt Ltd, Delhi, India and Carbopol-934 and Carbopol-980 are obtained from SigmaAldrich, Germany were used as received. Benzalkonium chloride was obtained from S.D Fine chemicals, Mumbai, 
India. All chemicals and solvents utilized were of HPLC grade. Throughout the study distilled water was used.

Determination of absorption maximum $\left(\lambda_{\max }\right)$ of Itraconazole and Construction of calibration curve:

Accurately weighed about $10 \mathrm{mg}$ of Itraconazole was dissolved in $2 \mathrm{ml}$ of $0.1 \mathrm{~N} \mathrm{HCl}$ properly, then solution of 10 $\mu \mathrm{g} / \mathrm{ml}$ was prepared using $\mathrm{pH} 6.8$ phosphate buffer and scanned in the range of 200 to $400 \mathrm{~nm}$ using Elico UV spectrophotometer, in order to determine the absorption maxima of Itraconazole ${ }^{5}$.

Accurately weighed about $10 \mathrm{mg}$ of Itraconazole was dissolved in $2 \mathrm{ml}$ of $0.1 \mathrm{~N} \mathrm{HCl}$ properly, followed by this added phosphate buffer to make the volume to $10 \mathrm{ml}$ and sonicated for 15 minutes to obtain concentration of 1000 $\mathrm{mcg} / \mathrm{ml}$. $1 \mathrm{ml}$ of stranded was taken and made the volume to $10 \mathrm{ml}$ with $\mathrm{pH}$ 6.8phosphate buffer to attain the concentration of stock solution $100 \mu \mathrm{g} / \mathrm{ml}$. Aliquots from the second stock solution were selected in a range of 1.0-5.0 $\mathrm{ml}$ to prepare concentrations of $10,20,30,40$ and $50 \mu \mathrm{g} / \mathrm{ml}$ with phosphate buffer $\mathrm{pH} 6.8$ and anaysed for absorbances by using Elico-UV spectrophotometer to construct the calibration curve.

\section{Formulation development and evaluation}

Itraconazole is low soluble drug, to increase its solubility it is converted into solid dispersion ${ }^{6}$. Solid dispersion of Itraconazole was prepared with Hydroxy- $\beta$-cyclodextrin in $1: 1,1: 2,1: 3$, and $1: 4 \mathrm{w} / \mathrm{w}$, drug : carrier ratio using 'Dry grinding method'-(F1-F4), 'Wet grinding method'-(F5-F8) and solvent evaporation method-(F9-F12) were shown in the tableno:1

Table 1: Formulation Table of Itraconazole Solid Dispersions

\begin{tabular}{|c|c|c|c|c|c|c|c|c|c|c|c|c|}
\hline \multirow{2}{*}{ Ingredients } & \multicolumn{4}{|c|}{ Dry grinding method } & \multicolumn{4}{|c|}{ Wet grinding method } & \multicolumn{4}{|c|}{ Solvent evaporation method } \\
\hline & F1 & F2 & F3 & F4 & F5 & F6 & F7 & F8 & F9 & F10 & F11 & F12 \\
\hline Itraconazole (mg) & 100 & 100 & 100 & 100 & 100 & 100 & 100 & 100 & 100 & 100 & 100 & 100 \\
\hline $\mathrm{HBCD}(\mathrm{mg})$ & 100 & 200 & 300 & 400 & 100 & 200 & 300 & 400 & 100 & 200 & 300 & 400 \\
\hline IPA:0.1N HCI(10\%v/v) (ml) & - & - & - & - & & & & & qs & qs & qs & qs \\
\hline Distilled water (ml) & & & & & qs & qs & qs & qs & qs & qs & qs & qs \\
\hline
\end{tabular}

\section{Selection of solid dispersion formulation for in-situ gel preparation}

All solid dispersions are analyzed to assess the solubility of Itraconazole which findings were concluded that the F12 has highest solubility among prepared solid dispersions. F12 has shown 27 times of solubility increased in comparison to pure drug shown in the table no: 2. An increase in the dissolution rate of Itaconazole has been attributed to the polar nature of the polymer, which increased the wettability of the drug and also due to decrease in its crystalinity when prepared as a solid dispersion by solvent evaporation method. Based on solubility test results, the solid dispersion formulation F12 was preferred as optimized formulation to design ocular in-situ gel.

Table 2: Solubility test results for solid dispersions

\begin{tabular}{|c|c|c|c|c|c|c|c|c|c|c|c|c|}
\hline Formulation & F1 & F2 & F3 & F4 & F5 & F6 & F7 & F8 & F9 & F10 & F11 & F12 \\
\hline $\operatorname{con}(\mu \mathrm{g} / \mathrm{ml})$ & 1.741 & 3.593 & 4.704 & 8.963 & 4.704 & 11.37 & 13.22 & 17.11 & 13.22 & 17.11 & 22.11 & 27.11 \\
\hline
\end{tabular}

\section{Preparation of ocular in-situ gels}

Total four ocular in-situ gel systems were designed by using different combination of Carbopol of two different grades as $\mathrm{pH}$ sensitive polymer, Hydroxy Propyl Methyl
Cellulose (HPMC) as viscosity enhancer and benzalkonium chloride as preservative. Based on $\mathrm{pH}$ triggered approach prepared Itraconazole ophthalmic in-situ gels and the composition of each formulation were shown in the table no:3.

Table 3: Formulation Table of Itraconazole Ocular In-situ Gels

\begin{tabular}{|c|c|c|c|c|}
\hline Ingredients & F1 & F2 & F3 & F4 \\
\hline Drug (\%w/V) & 1 & 1 & 1 & 1 \\
\hline HPMCk4(g) & 0.2 & 0.2 & - & - \\
\hline HPMC LVCR100(g) & - & - & 0.2 & 0.2 \\
\hline Carbopol 934(g) & - & 0.1 & 0.1 & - \\
\hline Carbopol 980 (g) & 0.1 & - & - & 0.1 \\
\hline Benzal konium Chloride & q.s & q.s & q.s & q.s \\
\hline Distilled water(ml) & 10 & 10 & 10 & 10 \\
\hline
\end{tabular}




\section{Characterization of formulation}

\section{FT-IR studies ${ }^{7}$}

IR spectra were recorded by using FTIR Fourier transformer infrared spectrophotometer (840, Shimadzu, Japan) to determine Interaction and compatibility in-between polymer and drug utilized in the formulation of insitu gel. FTIR spectra of pure drug Itraconazole and physical mixture of drug with excepients were obtained. The Spectral scanning of every sample was assessed in the range of 500 to $4000 \mathrm{Cm}^{-1}$ and resolution was at $1 \mathrm{Cm}^{-1}$. The FTIR spectra compatibility studies of drug with other polymers in the preparations of in situ gel have shown in Fig no: 3.

\section{Clarity}

The prepared Itraconazole in-situ gel formulations (F1-F4) were observed by naked eye for their characterization and clarity/nature of the preparations have to be determined under black \& white background with a swirling action by visual observation.

\section{Gelling capacity: Time and Nature}

The capacity of the gelation be assessed by placing one drop of the formulation in a watch glass containing $10 \mathrm{ml}$ of newly prepared synthetic tear fluid at ambient temperature $37^{\circ} \mathrm{C}$ and gelling time was observed visually. Coding for the gelling capacity described in Table no:4. The simulated tear fluid composition used was $670 \mathrm{mg}$ of $\mathrm{NaCl}$, $200 \mathrm{mg}$ of $\mathrm{NaHCO}_{3}, 8 \mathrm{mg}$ of $\mathrm{CaCl}_{2}$ dissolved in $100 \mathrm{ml}$ distil water.

\section{Rheological studies}

Viscosity of instilled formulation is a significant aspect to determining residence time of drug in the eye ${ }^{8}$. The purpose of the current investigation was to formulate an in-situ gel system and as of our earlier information we recognize that gels showed thixotropic behavior, so rheological studies are to be carried. Solutions of all are permitted to gel in Simulated Tear Fluid (STF) and then viscosity was measured. Viscosity measurements of solution and gels were carried out using Brook field viscometer-DVII. The formulations were developed positioned in the sampler holder using spindle no 61 Viscosity of every formulation was determined by utilizing Research Rotator and oscillatory rheometer. Rheological studies of developed formulation are shown in Table no:6.

\section{Measurement of $\mathrm{pH}$}

The $\mathrm{pH}$ is solitary key factor associated with the ophthalmic formulation. The $\mathrm{pH}$ of ophthalmic preparations with the goal of that should be stable at that $\mathrm{pH}$ and simultaneously on administration there would be no irritation. The ophthalmic preparation should be a $\mathrm{pH}$ range in between 5.6-6. Each developed formulations $\mathrm{pH}$ was evaluated using $\mathrm{pH}$ meter.

\section{Content percentage of drug}

The $5 \mathrm{ml}$ of ocular in-situ gel preparation was taken in $100 \mathrm{ml}$ of phosphate buffer $\mathrm{pH} 6.8$ buffer stirred under mechanical stirrer for complete dispersion of the gel then filtered followed by $1 \mathrm{ml}$ sample was taken diluted with phosphate buffer. By using UV visible spectrophotometer the absorbance of samples were measured at $255 \mathrm{~nm}$ and calculated the drug content percentage.

\section{Diffusion study in vitro}

The study of the diffusion of the sample was carried out using Franz diffusion apparatus method and diffusion media utilized is phosphate buffer ph6.8. $\mathrm{pH} 7.4$ buffer will simulate lachrymal fluid. $37^{\circ} \mathrm{C}$ temperature was maintained. At various time intervals samples were withdrawn and spectrophotometrically analyzed for drug content ${ }^{9}$.

\section{Microbiological studies}

The anti-microbiological studies are conducted to ascertain the biological action of optimized sol-to-gel formulation. The microbial efficiency was determined by using Diffusion Method (well diffusion technique). Sterile solution of pure drug was used as Standard. Standard and optimized formulation solutions were inoculated in well bored into sterile potato dextrose agar medium formerly seeded with test organism C.albicans and Aspergillus niger. followed by inoculation permit plates for diffusion of solution for two hours and incubated for $24-48 \mathrm{hrs}$ at $37^{\circ} \mathrm{C}$. The inhibitory zone effect of formulation was compared with that of the standard ${ }^{10}$.

\section{RESULTS AND DISCUSSION}

\section{$\lambda_{\max }$ of Itraconazole}

The absorption maxima, $\lambda_{\max }$ of Itraconazole by UV scan in phosphate buffer was at $255 \mathrm{~nm}$. The calibration curve of Itraconazole by plotting the concentration versus absorbance resulted in a straight line. Hence the result indicates that drug obeys Beer's law show in Fig $1 \& 2$.

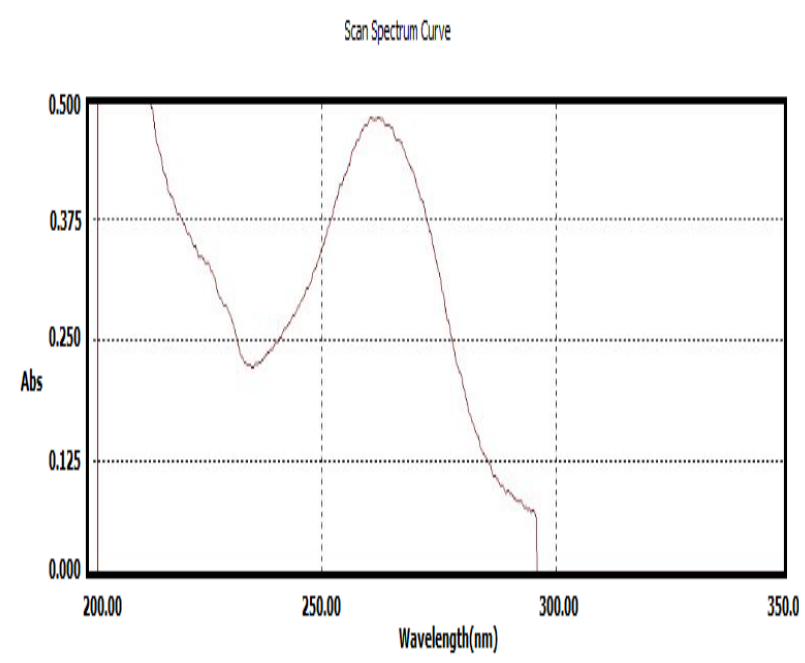

Figure 1: Itraconazole Absorption curve $\left(\lambda_{\max }: 255 \mathrm{~nm}\right)$ 


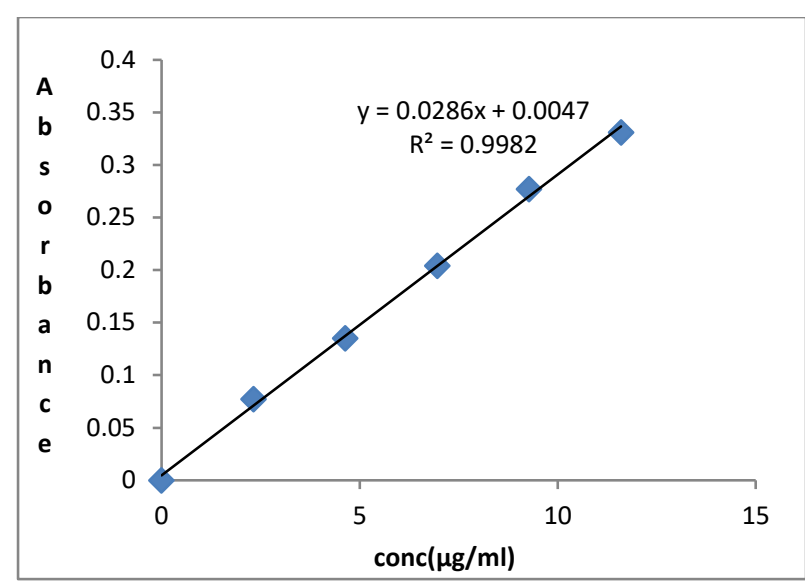

Figure2: Calibration curve of Itraconazole
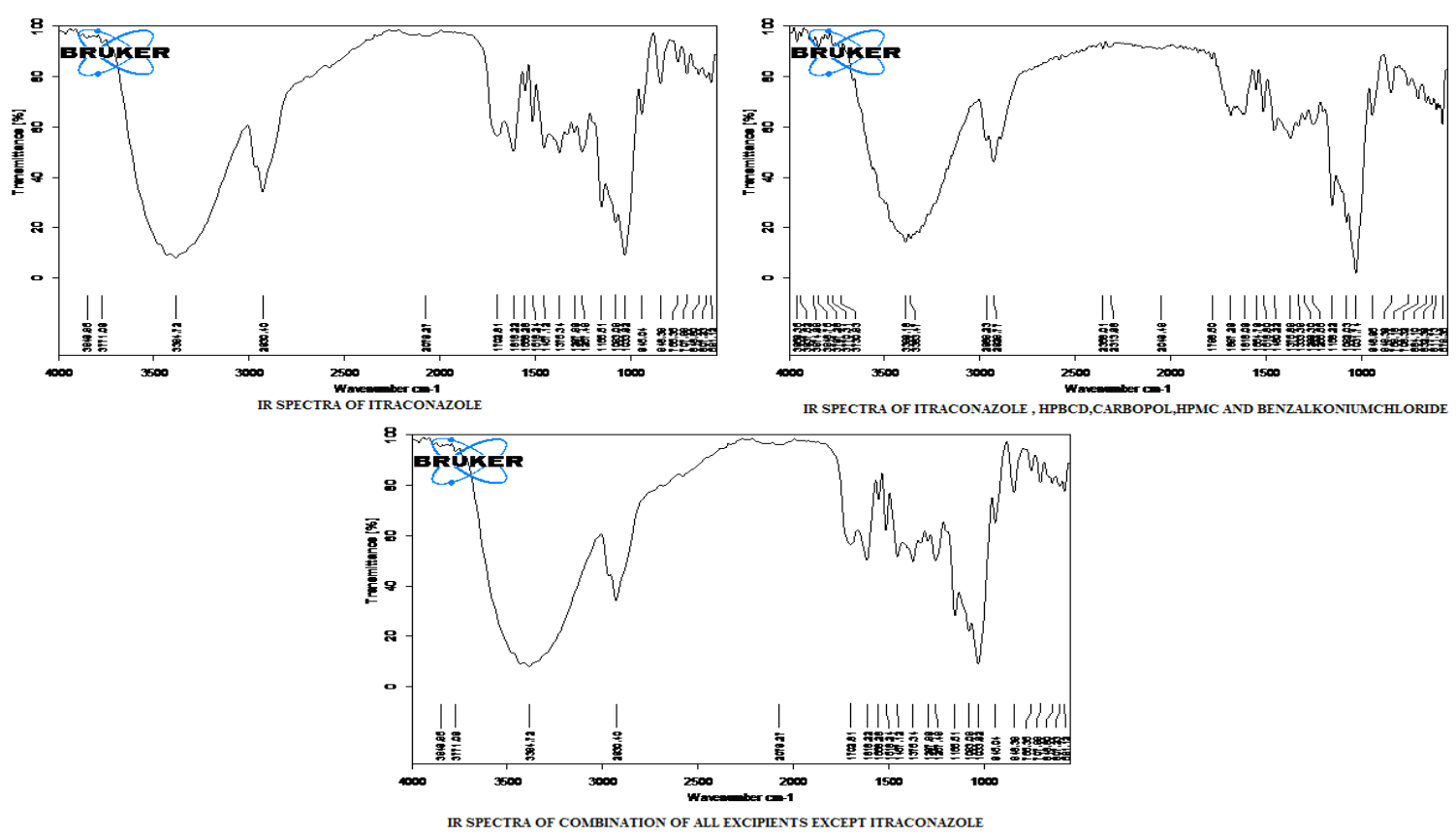

Figure 3: FTIR spectra of Itraconazole, polymers and physical mixture of drug with polymers

\section{pH and Clarity}

The prepared formulations F1toF4 all are clear with no turbidity and impurities. The $\mathrm{pH}$ of in-situ gel preparations was founded to be in between 5.6 to 6 . The optimum viscosity that allows easy ophthalmic instillation results are

\section{FT-IR: Drug polymers Compatibility studies}

Compatibility study of drug and mixture of drug with excipients (HPBCD, Carbopol, HPMC and Benzalkonium chloride) were performed by FTIR technique. The IR spectra of drug excipients study indicating that there is no interaction between Itraconazole and polymers. The major peaks were obtained almost at the same wave numbers which belonging to drug functional groups. On the other hand, in the physical mixtures additional peaks were obtained due to attendance of impurities however there is no influence in the drug peaks. The observation of spectral studies has indicating that there was no significant change in the peaks of drug polymer mixture. Therefore, no specific interaction between the drug and polymers was observed results were shown in Fig. no: 3.

Table 4: Evaluation results of $\mathrm{pH}$, gelling nature and appearance Formulations

\begin{tabular}{|c|c|c|c|c|c|}
\hline S. No & Formulation code & Appearance & pH & \multicolumn{2}{|c|}{ Gelling } \\
\hline 1 & F1 & Clear and transparent & $6.0 \pm 0.96$ & $1 \mathrm{Sec}$ & $+\mathbf{+ +}$ \\
\hline 2 & F2 & Clear and transparent & $5.6 \pm 1.94$ & $1 \mathrm{Sec}$ & ++ \\
\hline 3 & F3 & Clear and transparent & $5.8 .1 \pm 1.02$ & $1 \mathrm{Sec}$ & + \\
\hline 4 & F4 & Clear and transparent & $5.7 \pm 0.80$ & $1 \mathrm{Sec}$ & + \\
\hline+++ & - & Immediate gelation, very more thick & & & \\
\hline++ & - & Immediate gelation, more thick & & & \\
+ & - & immediate gelation, less thick and rapid dispersion & & \\
\end{tabular}

\section{Determination of drug content}

Content of drug in all F1toF4 formulations was determined and results are in the acceptable range. The ranges of drug shown in Table3.All formulations shown immediate gelation and transparent gel. carbopol acts as gelling agent and HPMC is viscosity contributor, The lesser the viscosity grade of HPMC lesser is its contribution in gel thickness and gelling capacity is coded as described in Table no 4. 
Table 5: Drug content data of formulations

\begin{tabular}{|c|c|c|c|c|}
\hline Formulation code & F1 & F2 & F3 & F4 \\
\hline \%Drug content & $94.94 \%$ & $98.94 \%$ & $99.98 \%$ & $93.65 \%$ \\
\hline
\end{tabular}

\section{Rheological Studies}

The viscosity of the formulations directs the action of the formulations in the cul de sac that resists against fluid mechanism and eye blink. Sequentially to evaluate the rheological activities, the viscosity of the formulation was evaluated before and once adding of simulated tear fluid using a viscometer. All formulations were established to be shear thinners showing pseudo plastic activity. All formulations were fluid at $25^{\circ} \mathrm{C}$ and undergo fast gel formation upon increasing the $\mathrm{pH}$ to 7.2. The each preparation was examined at $25^{\circ} \mathrm{C}$ and also at $37^{\circ} \mathrm{C}$. The outcomes of the viscosity studies prior and after gelling were conferred within the table no 6 . The viscosity of the each formulations actively increased because of the change in $\mathrm{pH}$ after instillation of the preparation into the tear film results in an approximately instantaneous transformation of the extreme fluid latex into a viscous gel.

Table 6: Rheological Studies: Viscosity of formulations before and after Gelling

\begin{tabular}{|c|c|c|}
\hline \multicolumn{3}{|c|}{ Rheological Studies of drug formulations } \\
\hline F-Code & Viscosity Before Gelling at $\mathbf{2 5}^{\circ} \mathbf{C}$ in cps & Viscosity After Gelling at $\mathbf{3 7}^{\circ} \mathbf{C}$ in cps \\
\hline F1 & $1290 \pm 1.89$ & $1498.3 \pm 2.1$ \\
\hline F2 & $762 \pm 6.01$ & $976 \pm 4.18$ \\
\hline F3 & $562.8 \pm 2.62$ & $883 \pm 6.04$ \\
\hline F4 & $996 \pm 4.38$ & $1164 \pm 2.93$ \\
\hline
\end{tabular}

\section{In vitro diffusion studies}

The in-situ gelling preparations of Itraconazole were subjected to in-vitro diffusion studies for time of $30 \mathrm{~min}$ shown in Table no:7 and fig no:4. At the end of 30min all formulation F1, F2 and F4 showed maximum 94.2\%, 102\% and $96 \%$ of cumulative drug release shown but in case of formulation $\mathrm{F} 3$ within first 5 to $10 \mathrm{~min} 100 \%$ of drug has released. Compare to all formulations based on the results of diffusion studies, F3 can be considered as optimized formulation as aim of study is fast release of the drug with in short duration because as the formed gel can't withstand in the eye for longer time to show controlled release as the lacrimal fluid try to wash out the gel.

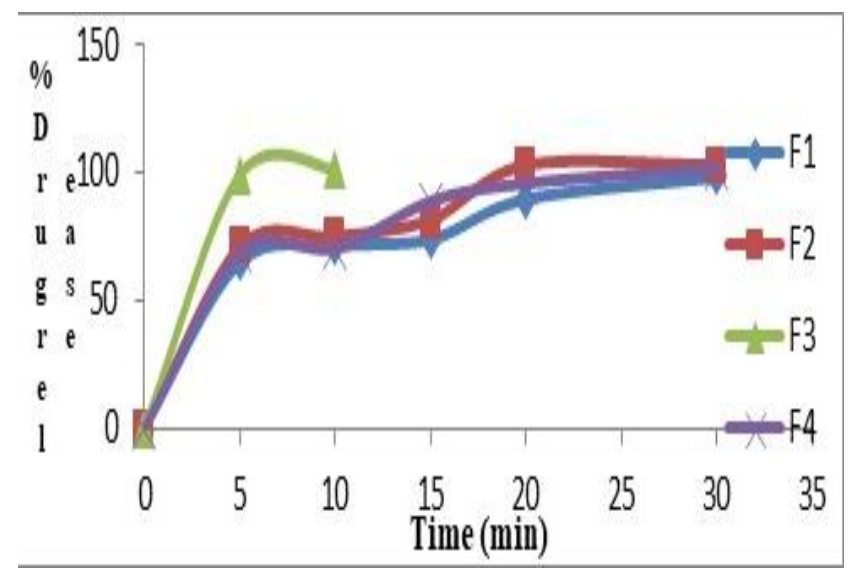

Figure 4: Comparative in-vitro diffusion studies of Formulations

According to the results obtained the commercial formulation (Itral $1 \% \mathrm{w} / \mathrm{V}$ suspension) is releasing less than $1 \%$ of drug with in 30 mins. but the optimize formulation is releasing complete $100 \%$ of drug within 10 min giving scope for maximum availability of the drug to get absorbed before it is drained by the lacrimal drainage. As the optimised formulation is not sustained release dosage form no need to maintain the dosage form for long period of time for complete release and to increase bioavailability.

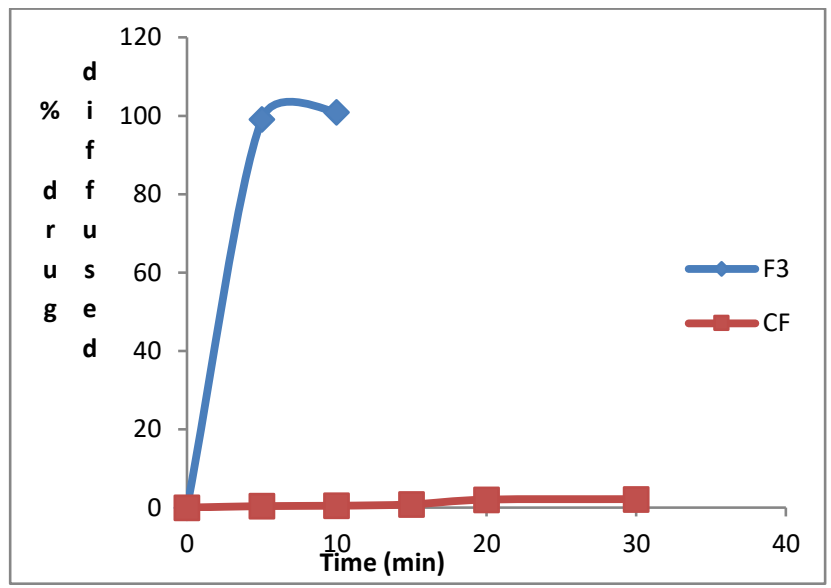

Figure 5: Comparison of in-vitro diffusion profile of optimized formulation with commercial formulation

\section{The anti-microbiological studies}

Antimicrobial activity: The result of the antimicrobial efficacy tests shown in (Figure 8). The study indicates that Itraconazole retained its antimicrobial activity after formulated into an in situ gel. The drug was active against Candida albicans and Aspergillus niger as indicated by zone of inhibition. 

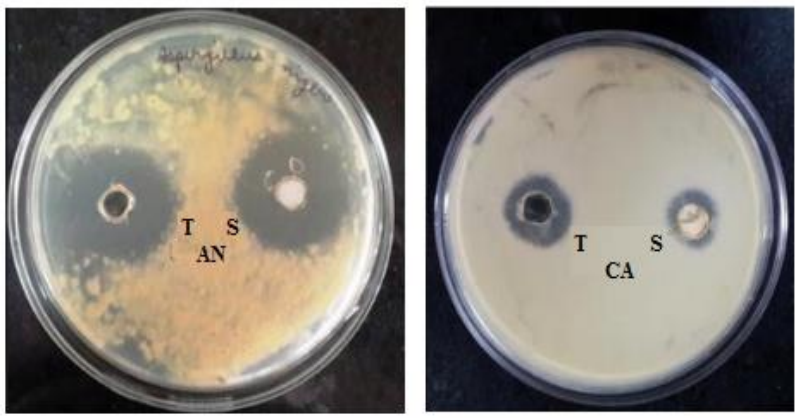

Figure 5: The antimicrobial efficacy test against Candida albicans and Aspergillus niger

AN: Aspergillus niger, CA: Candida albicans; T: Test, S: Standard

\section{CONCLUSION}

Itraconazole was effectively formulated as insitu gelforming ophthalmic preparation using HPMC and Carbopol 934. From this study, thus the above results demonstrate that HPMC and Carbopol mixture can be used as an in-situ gelling vehicle to prepare Itraconazole ophthalmic gels enhance ocular bioavailability. The developed formulation (F3) may prove to be a viable alternative to conventional eye drops and ointment in terms of ease of administration and rapid and complete release and absorption of drug which may ultimately result into improved patient compliance and it can be a promising antifungal against Candida albicans and Aspergillus niger. In order to maximize the potential of this system for ocular delivery further in vivo studies and stability studies are needed to examine. Ophthalmic in situ gels will be promising approach to overcome the drawbacks of conventional ophthalmic solutions. Hence further work is recommended to support its efficacy claims by in vivo studies and stability studies.

\section{REFERENCES}

1. Kanoujia J, Kanchan S, Panday M, Shubhini AS, Koshy MK. Formulation and characterization of a novel $\mathrm{pH}$-triggered insitu gelling ocular system containing Gatifloxacin. Int. Curr. Pharma. J, 2012; 1(3): 43-49.

2. M.K. Thimmasetty,S.Mandal,G.L.Prabhushankar,M.S.Geetha. Formulation and evaluation of an insitu gel of amoxicillin trihydrate, Int.J.Pharm.Investig. 2012: 2 (2): 78-82.

3. Ashim KM. Ophthalmic drug delivery system. Vol 58. New York: Marcel Dekker Inc; 1993; p. 105-10.

4. Kaur IP, Garg A, Singla AK, Aggarwal D. Vesicular systems in ocular drug delivery an overview. Int J Pharm 2004; 269: 1-14.

5. S.Chelladurai, M.Mishra, B.Mishra, Design and evaluation of bioadhesive in-situ nasal Gel of ketorolac tromethamine,Chem.Pharm.Bull. 2008;56(11): 1596-1599.

6. Van-Thanh T., Vinh P.V.Q., Van-Hoa H. () Research and Preparation of Solid Dispersion of Itraconazole in Hydroxypropyl-Beta-Cyclodextrin. In: Toi V., Lien Phuong T.5th International Conference on Biomedical Engineering in Vietnam. IFMBE Proceedings, 2015; vol 46: Springer, Cham. https://doi.org/10.1007/978-3-319-11776-874.

7. C. Nagesh, M.Patil, S.Chandrashekhara, R.Sutar, A novel insitu gel for sus- tained ophthalmic delivery of ciprofloxacin hydrochloride and dexamethasone design and characterization,Pharm.Lett. 2012; 4(3): 821-827.

8. Udaya K. Kotreka, Vicki L. Davis, Moji C. Adeyeye Development of topical ophthalmic In Situ gel forming estradiol delivery system intended for the prevention of agerelated cataracts, Plos One, 2017; 2(3): 1-10.

9. The Indian Pharmacopoeia, The Indian Pharmacopoeia Commission: Ghazia- bad, India, Published by Ministry of Health and Public Welfare, Government of India, New Delhi 2010; vol. 2: p. 1032.

10. Kumar Raja JK, Muralidharan S, Formulation and In vitro Evaluation of Gellan Gum/Carbopol and Sodium Alginate based Solution to gel depot of ketootifen Fumarat System, Int. J. Pharm. \& Pharma. Sci, 2012; 4(11): 1973-1977.

Source of Support: None declared.

Conflict of Interest: None declared.

For any question relates to this article, please reach us at: editor@globalresearchonline.net New manuscripts for publication can be submitted at: submit@globalresearchonline.net and submit_ijpsrr@rediffmail.com 